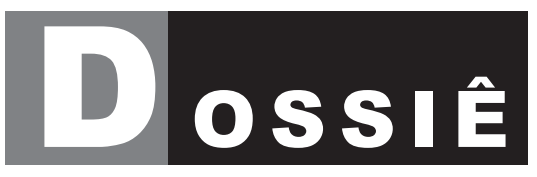




\section{Politização da cultura e participação social entre Brasil e Argentina: territórios e memórias em disputa}

Politization of culture and social participation between Brazil and Argentina: territories and memories in dispute

\section{Renata de Sá Gonçalves}

Professora do Departamento de Antropologia e do Programa de Pós-graduação em Antropologia da Universidade Federal Fluminense (UFF). Coordena o Núcleo de Antropologia das Artes, Rituais e Sociabilidades Urbanas (NaRua/UFF). Atua principalmente com os seguintes temas: cultura popular, festas (carnaval), ritual e simbolismo, políticas culturais, educação, gestão e preservação do patrimônio cultural. Jovem Cientista do Nosso Estado (Faperj) e Bolsista de Produtividade (CNPq).

\section{Julieta Infantino}

Professora e Doutora em Antropologia pela Universidad de Buenos Aires. Pesquisadora assistente do Consejo Nacional de Investigaciones Científicas y Técnicas (Conicet). Integrou diversas equipes vinculadas ao estudo das culturas populares e políticas culturais, assim como da questão juvenil e da antropologia urbana. Atua principalmente com o estudo das relações entre juventudes, artes populares (circenses) e políticas culturais.

Nas últimas décadas, passamos por um processo de ampliação e pluralização do conceito de "cultura", que transcende a disciplina antropológica e a própria academia. De concepções idealizadas, essencialistas e restritas, passamos a conceber a noção de cultura de maneira ampliada, destacando sua diversidade, seus usos e interseções com outros âmbitos, como o econômico e o político. Culturas, artes, memórias, saberes e tradições são "recursos" que servem a propósitos variados (YÚDICE, 2002), desigualmente apropriados por diferentes atores sociais. Assim, agências internacionais, instâncias governamentais, movimentos sociais, coletivos étnicos, artísticos, entre outros, "usam" e apelam a noções de "cultura" para os mais diversos fins. Podemos citar o seu uso presente em políticas públicas, como ferramenta para o desenvolvimento econômico, para a promoção da diversidade e da coesão social, para gerenciar o risco social em sociedades cada vez mais impactadas pelas consequências do neoliberalismo, ou, ainda, como um instrumento de demanda 
e de disputa política no processo de politização da cultura (WRIGHT, 2004; INFANTINO, 2019).

Os artigos reunidos neste dossie $\hat{e}^{1}$ buscam problematizar, a partir de situações empíricas de pesquisa especialmente no Brasil e na Argentina, como as produções culturais de diversos grupos sociais, nesses dois países, renovam e mobilizam memórias, conhecimentos e recursos políticos, culturais, organizativos, econômicos e identitários, dando visibilidade a novas disputas dentro do espaço público. Neste campo de negociações, os setores historicamente subalternizados, jovens da "periferia” urbana (ADERALDO, 2017), grupos indígenas (CRESPO, 2013a), artistas populares (MOREL, 2011), grupos étnicos (VASSALLO; CICALO, 2015; BITTER, 2015) acionam e se organizam coletivamente por meio de associações e projetos "culturais" em resposta a políticas e projetos de modernização de cidades e territórios.

Assim, os processos de uso e ressignificação dos espaços - cidades, territórios, instituições - colocam em cena formas de dramatização dos pertencimentos identitários mediadas pela apresentação da "cultura" (como linguagem e estratégia de interação) para construção de posicionamentos públicos e negociações da realidade. Espaços, territórios e lugares não são apenas cenário, mas construções sociais que se atualizam e são disputadas.

Nesse jogo, a relação com o Estado, por meio de seu aparato de gestão política, ganha centralidade, adotando parâmetros, ações e legislação que dialogam com a dinâmica de produção e reprodução das manifestações expressivas e as memórias dos distintos grupos. Estes, por sua vez, disputam pelo reconhecimento de suas identidades e pertencimentos, seus direitos e recursos. As políticas, longe de serem o produto de vontades hegemônicas unidirecionais, resultam da negociação entre distintos setores dentro do aparato estatal, agências, movimentos sociais, organizações da sociedade civil, grupos

\footnotetext{
A proposta deste dossiê surgiu de um projeto conjunto de pesquisa entre Brasil e Argentina, desenvolvido em cooperação entre a UFF e a UBA, com coordenação de Alessandra Barreto (UFF) e Alícia Martín (UBA) financiado pela Coordenação de Aperfeiçoamento de Pessoal de Nível Superior (Capes) e o Ministério de Educação, Cultura, Ciência e Tecnologia (MinCyt) argentino. A publicização dos trabalhos e dos debates aqui desenvolvidos reflete a produção e interlocução entre antropólogos e antropólogas de ambos os países que, desde 2014, vêm se reunindo em diferentes oportunidades e em grupos de trabalho da área de Antropologia, especialmente a Reunião de Antropologia do Mercosul (RAM).
} 
comunitários, movimentos indígenas e produtores culturais. Manuela Carneiro da Cunha (2009), em sua discussão sobre a cultura com aspas propõe pensar os paradoxos e reflexividade entre uma visão - ou uso - pragmático da cultura por parte dos grupos étnicos e seus "esquemas interiorizados" de percepção, ação e comunicação. Haveria, assim, em função dos processos legais de seus reconhecimentos como sujeitos de direito, estímulo à criação de novas formas associativas.

No Brasil, com base especialmente na ordem discursiva pós-Constituição Federal de 1988, as políticas culturais estiveram a serviço da construção de uma agenda pública para a diversidade. Na produção desta agenda, as diferenças culturais passaram a informar as construções narrativas a respeito das novas noções de cidadania, reivindicadas e negociadas por movimentos sociais junto ao Estado e aos governos. No Brasil, essas transformações podem ser associadas às mudanças semânticas e políticas que incorporaram a moderna concepção antropológica de cultura ao campo das políticas públicas (MOTTA; OLIVEIRA, 2015). A ampliação de sentidos e de usos da noção de "cultura" também está inscrita no âmbito de uma nova ordem discursiva internacional sobre direitos humanos e suas derivações nos direitos culturais (MOTTA, 2018).

Especialmente na última década, no sentido contrário aos processos de privatização e encerramento dos espaços, do consumismo e do individualismo, impulsionados por uma intensificação de políticas neoliberais, distintos coletivos sociais conformaram, na Argentina e no Brasil, novos espaços de sociabilidades e de atuação. Grupos culturais, associações e coletivos diversos adquiriram centralidade nas sociedades contemporâneas ao canalizar os modos de ação de novos sujeitos coletivos no espaço público. Nesse processo, a dimensão política das expressões culturais surge como um aspecto fundamental dos processos de construção identitária. Tais práticas culturais de oposição ao neoliberalismo devem ser entendidas como formas de atuação política não institucionalizada. Assim, "la carnavalización de la protesta, la dramatización de los referentes identitarios, la imaginación para captar la atención de los medios de comunicación, trastoca las relaciones en el espacio público y señala la transformación en los modos de hacer política" (REGUILLO CRUZ, 2000, p. 148). 
Isso fica mais evidente se consideramos as performances culturais como dispositivos de mediação e integração intercultural, em situações assimétricas frente ao poder e, ao mesmo tempo, como ação criadora de discursos que remetem a um passado conflitivo (BAUMAN, 1992a; 1992b; 1992c; 1992d; MARTÍN, 2008; MOREL, 2011; ANNECCHIARICO 2011; MERCADO, 2018). Novas demandas políticas, diferentes tanto dos canais de participação política tradicionais como das práticas culturais, já não se circunscrevem apenas a espaços de consagração e prestígio (WORTMAN, 2010; INFANTINO, 2012).

Neste contexto, algumas expressões do folclore, da cultura popular e da tradição afro e indígena, tempos atrás reduzidas a formas culturais em processo de extinção ou pré-modernas, são promovidas a paliativos locais às crises macroestruturais. As artes, a dança (GONÇALVES, 2010; MOREL, 2011) e a educação (BARRETO, 2018) canalizam uma integração notável de algumas destas expressões e saberes, por meio de processos de lutas e de resistências que confrontam práticas já estabelecidas. Sobretudo, nas áreas das políticas públicas e dos organismos internacionais, tais práticas passam a regular a "diferença permitida” em detrimento daquela não tolerada (CANALE; MOREL, 2005; HALE, 2006; CRESPO et al., 2007; MOREL, 2011; INFANTINO, 2012).

Aqui, a abrangência das políticas culturais, tanto no contexto brasileiro como no argentino, emerge como arena de negociações e disputas entre diferentes agentes desigualmente posicionados, e como espaço propício para analisar modalidades de participação social (MARTÍN, 2008; GONÇALVES; FERRO, 2018). Assim, se soma à esfera da administração estatal o fortalecimento de uma noção de patrimônio categorizado como "patrimônio vivo" (GARCÍA CANCLINI, 1994), "imaterial", "intangível”, representado por expressões do folclore, do indígena, do afroamericano e da cultura popular. Diante desse cenário, um novo elemento deve ser considerado na reflexão contemporânea sobre o patrimônio cultural. "O avanço das políticas de patrimônio imaterial e o campo das expressões culturais não podem ser pensados sem considerarmos sua relação com a trajetória e os grupos produtores, que emergem como sujeitos ativos e atuantes dentro dos processos de patrimonialização" (GONÇALVES; TAMASO, 2018, p. 458). 
Nestes processos, emergem memórias subterrâneas (POLLAK, 2006) com as quais se disputa o direito a novos arranjos para os grupos subalternizados, invisibilizados pelas grandes narrativas da nação e pelos projetos de urbanização e de desenvolvimento. As localidades e as memórias, assim como as práticas culturais e identitárias, se convertem em lugares políticos e assim se demanda poder, participação e reconhecimento (VASSALLO; CICALO, 2015; BITTER, 2015; CRESPO, 2013b).

Assim, no primeiro artigo "Memórias, experiências e saberes em contextos de retomada territorial mapuche em El Hoyo, Chubut (Patagônia, Argentina)", Carolina Crespo se dedica a investigar os processos de construção de memória, esquecimento e silêncio dos povos nativos da Patagônia Argentina. Nos últimos anos, a antropóloga argentina tem se dedicado a investigar os processos de reivindicações de terras mapuches na Região Andina do Paralelo $42^{\circ}$ no noroeste da província de Chubut e no sudoeste da província de Rio Negro a fim de examinar como as memórias e os silêncios desses setores foram subalternizados, conformando territórios, temporalidades e subjetividades em processos de disputa. A autora examina, por meio de uma abordagem etnográfica e de trabalho de arquivo, memórias, conhecimentos e experiências mapuches que se colocaram em cena neste processo, continuidades e rupturas, bem como o papel das mulheres indígenas em contextos de luta pelo território e na transmissão de saberes mapuche. Crespo busca demonstrar como esses saberes e memórias se tornaram objetos de reflexão e agenciamento político em múltiplos sentidos. De um lado, desafiaram histórias e silêncios cristalizados e deslocaram categorias e subjetividades assumidas e imputadas. Por outro, se configuraram como diretrizes a partir das quais foram sendo organizados, definidos, e tornados inteligíveis e legitimados o espaço territorial de resistência e as formas de luta. Finalmente, colocaram em discussão certos modelos hegemônicos associados à "feminilidade" e à "masculinidade".

O artigo "Aprender a dançar tango em Buenos Aires: processos de transmissão e políticas culturais locais" de Hernán Morel tem como foco estudar os aspectos políticos, econômicos e performativos do baile social do tango na cidade de Buenos Aires a partir da pós-ditadura (1983) na Argentina. Sua 
pesquisa trata do chamado "tango de pista", modo participativo de dança que se desenvolveu no campo das "milongas" ou "salões de baile" portenhos, com especial atenção à dinâmica de transmissão, tradicionalização e renovação que produzem os próprios grupos de dançarinos, como também às articulações com diferentes políticas culturais desenvolvidas pela Prefeitura. O autor analisa como esse período pós-ditadura foi acompanhado pelo gradativo ressurgimento da dança de tango em nível local. O processo de ensino do tango se vincula a um conjunto de intervenções culturais produzidas durante esse período: uma sequência de ações, projetos e políticas culturais públicas que visavam favorecer o ensino e transmissão da dança. Assim, o autor enfatiza algumas características singulares dessas atividades de intervenção, levando em consideração que as narrativas atuais em torno do ressurgimento do tango dançado costumam invisibilizar tais iniciativas culturais. Na tentativa de superar tais invisibilizações, destaca o papel desempenhado por certos atores envolvidos, especialmente os professores(as) e milongueiros(as), em relação às novas gerações que se aproximavam pela primeira vez do tango dançado.

No artigo "Visualidades urbanas e poéticas da resistência: reflexões a partir de dois itinerários de pesquisa", Guilhermo Aderaldo busca demonstrar o modo como uma série de jovens integrantes de coletivos dedicados a diferentes modalidades de ativismo cultural em cidades como São Paulo, Rio de Janeiro e Buenos Aires têm se valido do uso "tático" de ferramentas tecnológicas, gráficas e comunicativas, com o propósito de produzir referenciais simbólicos capazes, por um lado, de interpelar crítica e publicamente determinados imaginários hegemônicos sobre territórios e populações marginalizadas e, por outro, de formular teorias originais, que sirvam de alternativa epistêmica para entender as relações de poder que modulam o governo dos espaços e das populações nas cidades sul-americanas contemporâneas. Para isso, retoma um conjunto de dados produzidos no decorrer de duas pesquisas etnográficas recentes, envolvendo o tema da relação entre juventudes, ativismos culturais e novas mobilidades.

Daniel Bitter e Simone Pondé Vassallo, em seu artigo "A múltipla Pequena África no Rio de Janeiro: perspectivas reflexas de negros e judeus", refletem 
sobre os processos de produção e reconfiguração dos espaços urbanos, pensando a cidade do Rio de Janeiro a partir de um ponto de vista processual que privilegia as tensões e as transformações que a atravessam. Para tanto, procuram pensar as dinâmicas de produção de narrativas e experiências contemporâneas acerca do território que veio a ser conhecido como a "Pequena África" no Rio de Janeiro, tentando compreender como entrelaçam pessoas e lugares, muitas vezes de forma tensa e disputada. Os autores argumentam que a Cidade Nova, através de seus dois pontos centrais - a antiga Praça Onze e o Campo de Santana - foram palco de uma intensa vida cosmopolita e intercultural, abrigando imigrantes portugueses, espanhóis, italianos, ciganos, judeus, além de significativa população afrodescendente.

Os autores partem da perspectiva de Michel Agier (2011), para quem a cidade é um significante vazio cujos múltiplos e possíveis sentidos são elaborados situacionalmente pelos atores sociais. Nesse sentido, a Pequena África no Rio de Janeiro foi, sem dúvida, território onde se manifestou uma interação do tipo "porosa", sendo um marco simbólico de encontros e da produção de certos gêneros musicais que se tornariam emblemáticos da identidade carioca. A presença de judeus refugiados do Leste Europeu é particularmente notória no entorno da antiga Praça Onze, onde se fixaram nas primeiras décadas do século XX. Ali, ao lado da comunidade negra e de outros imigrantes, os judeus também desenvolveram uma intensa vida social e cultural, deixando marcas de seus costumes na cultura carioca. Neste artigo, os autores exploram como se constroem as memórias de negros e de judeus e os modos como se aciona o passado, no presente, de modo a demandar reconhecimento e visibilidade por meio de práticas artísticas e culturais.

As estratégias que acionam pertencimentos e memórias em disputa aqui apresentados no dossiê em seus respectivos contextos etnografados nos levam a refletir sobre a politização da cultura e sobre os modos de participação social na atualidade, servindo de estímulo para novas investigações e reflexões. 


\section{REFERÊNCIAS}

1. AGIER, Michel. Antropologia da cidade: lugares, situações, movimentos. São Paulo: Terceiro Nome, 2011.

2. ADERALDO, Guilhermo. Reinventando a cidade: uma etnografia das lutas simbólicas entre coletivos culturais vídeo-ativistas nas "periferias" de São Paulo. São Paulo: Annablume, 2017.

3. ANNECCHIARICO, Milena. Un estudio antropológico de la africanía cubana entre identidad, memoria y política. In: GUZMÁN, Florencia; GELER, Lea (coord.). Actas de las Segundas Jornadas de Estudios Afrolatinoamericanos del GEALA: Instituto Guzmán - Universidad de Buenos Aires. Buenos Aires: Mnemosyne, 2011. p. 687-703.

4. BARRETO, Alessandra Siqueira. Ocupa ICHF: processos de luta e artes de fazer entre estudantes universitários em Niterói, Rio de Janeiro. In: GONÇALVES, Renata; FERRO, Ligia (org.). Cidades em mudança: processos participativos em Portugal e no Brasil. Rio de Janeiro: Mauad, 2018. p. 177-196.

5. BAUMAN, Richard. El arte verbal como actuación. In: UNIVERSIDAD DE BUENOS AIRES. Serie de Folklore 14. Buenos Aires: Universidad de Buenos Aires, 1992a. p. 3-56.

6. BAUMAN, Richard. Folklore. In: BAUMAN, Richard (ed.). Folklore, cultural performances and popular entertainments: a communications-centered handbook. Oxford: Oxford University Press, 1992b. p. 29-40.

7. BAUMAN, Richard. Performance. In: BAUMAN, Richard (ed.). Folklore, cultural performances and popular entertainments: a communications-centered handbook. Oxford: Oxford University Press, 1992c. p. 41-49.

8. BAUMAN, Richard. Genre. In: BAUMAN, Richard (ed.). Folklore, cultural performances and popular entertainments: a communications-centered handbook. Oxford: Oxford University Press, 1992d. p. 53-59.

9. BITTER, Daniel. Narrativas de memória e performances musicais dos judeus cariocas da Pequena África. Antropolítica, Rio de Janeiro, n. 39, p. 121-149, 2015.

10. CANALE, Analía; MOREL, Hernán. Actores y representaciones en la patrimonialización de las agrupaciones del carnaval porteño. Cuadernos de Antropología Social, Buenos, Aires, n. 21, p. 111-131, 2005.

11. CRESPO, Carolina; LOSADA, Flora; MARTÍN, Alicia. Introducción. In: Patrimonio, políticas culturales y participación ciudadana. Buenos Aires: Antropofagia, 2007. p. 5-11. 
12. CRESPO, Carolina. Memorias de silencios en el marco de reclamos étnico-territoriales: experiencias de despojo y violencia en la primera mitad de siglo XX en el Parque Nacional Lago Puelo (Patagonia, Argentina). Cuicuilco, México, DF, v. 21 , n. 61 , p. 165-187, 2013 a.

13. CRESPO, Carolina (org.). Tramas de la diversidad: patrimonio y pueblos originarios. Buenos Aires: Antropofagia, 2013b.

14. CUNHA, Manuela Carneiro da. "Cultura" e cultura: conhecimentos tradicionais e direitos intelectuais. In: CUNHA, Manuela Carneiro da. Cultura com aspas e outros ensaios. São Paulo: Cosac Naify, 2009. p. 311-373.

15. GARCÍA CANCLINI, Néstor. ¿Quiénes usan el patrimonio? Políticas culturales y participación social. In: VILLAFRANCA, Jaime Cama; WITKER, Rodrigo Barra (coord.). Memorias del Simposio Patrimonio y Política Cultural para el siglo XXI. México, DF: Instituto Nacional de Antropología y Historia, 1994. p. 51-68. (Coleção Científica, 296).

16. GONÇALVES, Renata de Sá. A dança nobre do carnaval. Rio de Janeiro: Aeroplano, 2010.

17. GONÇALVES, Renata de Sá; FERRO, Ligia (org.). Cidades em mudança: processos participativos em Portugal e no Brasil. Rio de Janeiro: Mauad, 2018.

18. GONÇALVES, Renata de Sá; TAMASO, Izabela. A antropologia nos processos de patrimonialização: expansão e perspectivas. In: SOUZA LIMA, Antonio Carlos; BELTRÃO, Jane; LOBO, Andrea; CASTILHO, Sergio; LACERDA, Paula; OSORIO, Patricia (org.). A antropologia e a esfera pública no Brasil: perspectivas e prospectivas sobre a Associação Brasileira de Antropologia no seu $60^{\circ}$ aniversário. Rio de Janeiro: E-papers, 2018. p. 451-465.

19. HALE, Charles. El protagonismo indígena, las políticas estatales y el nuevo racismo en la época del 'indio permitido'. In: CONSTRUYENDO LA PAZ: GUATEMALA DESDE UN ENFOQUE COMPARADO, 2004, Guatemala. Anais [...]. Guatemala: Misión de Verificación de las Naciones Unidas en Guatemala, 2004. Disponível em: https://bit.ly/2IBDXO3. Acesso em: 15 abr. 2019.

20. INFANTINO, Julieta. Cultura, jóvenes y políticas en disputa: prácticas circenses en la ciudad de Buenos Aires. 2012. Tese (Doutorado em Ciências Antropológicas) - Facultad de Filosofía y Letras, Universidad de Buenos Aires, Buenos Aires, 2012.

21. INFANTINO, Julieta. Políticas culturales, arte y transformación social: recorridos, usos y sentidos diversos en espacios de disputa. In: INFANTINO, Julieta (ed.). Disputar la cultura: arte y transformación social en la ciudad de Buenos Aires. Caseros: RGC, 2019. p. 19-63. 
22. MARTÍN, Alicia. Folclore en el Carnaval de Buenos Aires. 2008. Tese (Doutorado em Ciências Antropológicas) - Facultad de Filosofía y Letras, Universidad de Buenos Aires, Buenos Aires, 2008.

23. MERCADO, Camila. Trayectorias de Teatro Comunitario en Buenos Aires: políticas culturales, autogestión y sentidos del arte en disputa. 2018. Tese (Doutorado em Antropologia) - Facultad de Filosofía y Letras, Universidad de Buenos Aires, Buenos Aires, 2018.

24. MOREL, Hernán. Políticas culturales y performances en los procesos patrimoniales: los casos del tango y el carnaval en la Ciudad de Buenos Aires. 2011. Tese (Doutorado em Ciências Antropológicas) - Facultad de Filosofía y Letras, Universidad de Buenos Aires, Buenos Aires, 2011.

25. MOTTA, Antonio; OLIVEIRA, Luiz. Prólogo: a "cultura" na agenda de direitos e políticas públicas (2003-2015). Anthropológicas, Recife, v. 26, n. 2, p. 1-16, 2015.

26. MOTTA, Antonio. Memórias plurais e direitos culturais. Outros Tempos, São Luís, v. 15. n. 25, p. 84-94, 2018.

27. POLLAK, Michael. Memoria, olvido, silencio: la producción social de identidades frente a situaciones límite. La Plata: Al Margen, 2006.

28. REGUILLO CRUZ, Rossana. Emergencia de culturas juveniles: estrategias del desencanto. Buenos Aires: Norma, 2000.

29. VASSALLO, Simone Pondé; CICALO, André. Por onde os africanos chegaram: o Cais do Valongo e a institucionalização da memória do tráfico negreiro na região portuária do Rio de Janeiro. Horizontes Antropológicos, Porto, Alegre, ano 21, n. 43, p. 239-271, 2015.

30. WORTMAN, Ana (org.) Entre la política y la gestión de la cultura y el arte: nuevos actores en la Argentina contemporánea. Buenos Aires: Eudeba, 2010.

31. WRIGHT, Susan. La politización de la 'cultura'. In: BOIVIN, Mauricio; ROSATO, Ana; ARRIBAS, Victoria. Constructores de otredad: una introducción a la antropología social y cultural. Buenos Aires: Antropofagia, 2004. p. 128-141.

32. YÚDICE, George. El recurso de la cultura: usos de la cultura en la era global. Barcelona: Gedisa, 2002. 